\title{
المعالجة الاخراجية لشخصية المقدس في الخطاب الدراهي
}

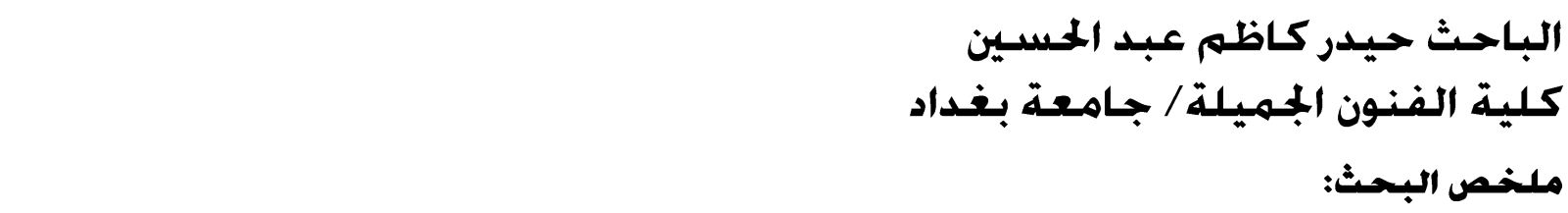

دخلت السينما منذ ولادتها الى يومنا هذا في جميع مجالات الحياة وعالجت كل أنواع القصص والحكايات سواء الواقعية منها أو الو القوات

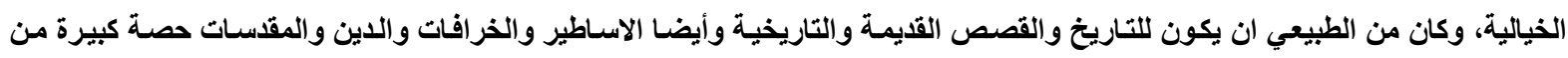

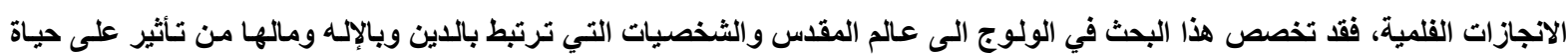

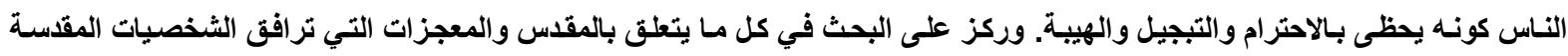

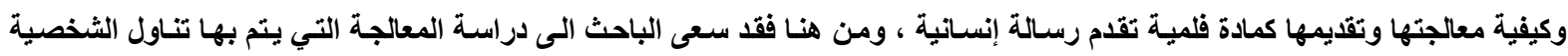

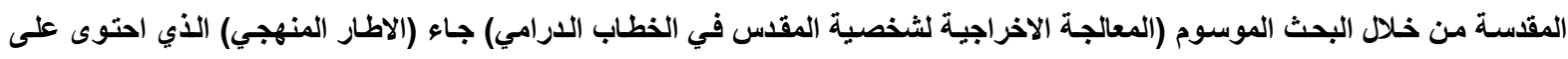

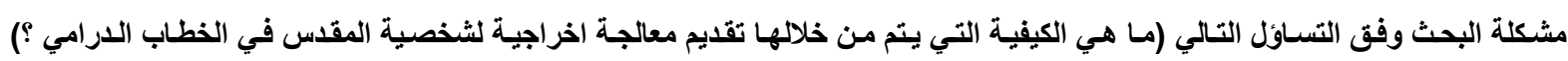

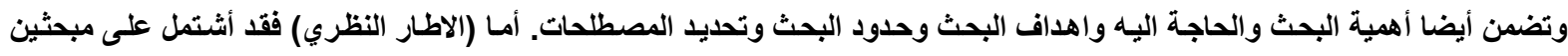

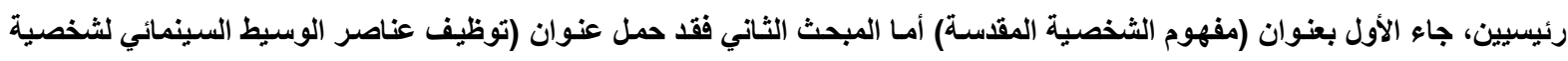

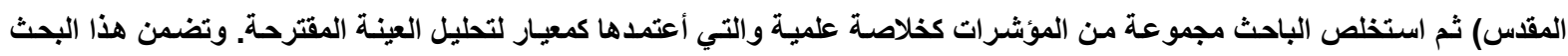

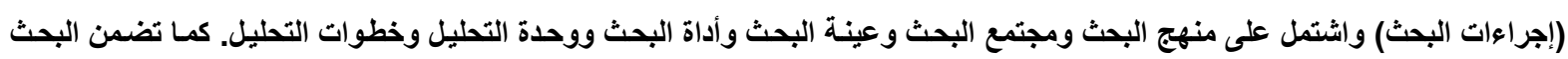

أيضا على (تحليل العينة) وتم فيه تحليل العينة المختارة ومناقشتها واستخلاص أبرز المشاهد واللقطات فيها وتحليلها وفق مؤشرات الإطار

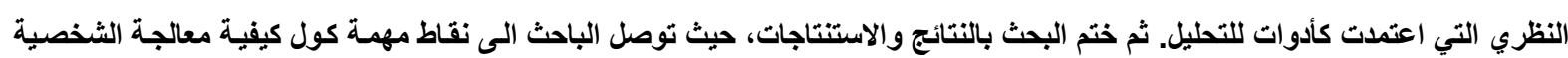

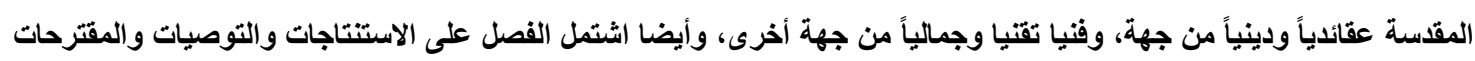

Summary

Since its birth, cinema has entered into the present day in all areas of life and has dealt with all kinds of stories and stories, both real and fictional, and it was natural that history and old and historical stories as well as legends, myths, religion and holy places a large share of film achievements, this research is dedicated to access to the world The sacred and the personalities that are related to religion and the God and its money have an impact on the lives of people as being respected, revered and respected.

The researcher sought to study the treatment of the Holy Person through the research of the character of the Holy Person in the dramatic discourse, It came in five chapters. The first chapter was entitled (The methodological framework) and it contains the problem of research according to the following question (how is it to provide a step-by-step treatment of the character of the sacred in the dramatic discourse?) This chapter also includes the importance of research and its need, To discuss and define terms.

The second chapter titled "The Concept of the Sacred Personality" was titled "The Employment of Elements of the Media Intermediary for the Personality of the Holy One". The researcher then concluded a series of indicators as a scientific and knowledge summary of Chapter $r, I$ adopt it as a standard for the proposed sample analysis.

This chapter concludes with previous studies.

This research included a third chapter entitled (Research Procedures), which included the research methodology, the research community, the research sample, the research tool, the analysis unit, and the analysis steps. 
The study also included the fourth chapter under the title (sample analysis), in which the selected sample was analyzed and discussed, and the most prominent scenes and snapshots were analyzed and analyzed according to theoretical framework indicators adopted as tools.

\section{(الاطار المنهـجي)}

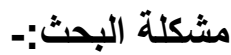

زخرت السينما العالمية بالعديد من المواضيع والافكار التي عالجتها سواء كانت لاحداث وشخصيات

اسطورية او تأريخيه او خياليـة وتقديمها ضمن اطـار درامي تشكل الاثارة والابهار جزءا كبير ا من محتو اه و التي يتلاعب بصياغتها السيناريست او المخرج بكمية الافكار التي يحملها او نوعية الجمهور الذي يستهدفه، بالإضـافة الـى المؤسسـات الانتاجيـة التي يحدد اشتغالها شبالك التذاكر ـ ومـن المو اضيع التـي تناولتهـا السينما العالمية هو المقدس انطلاقا من كون الفن السابع من اقوى وسائل التعبير عن الافكار والمعتقدات خصوصـا مـع التطور التقني الهائل الذي ساهم بتجسيد الاحداث التي نرافق المقدس من معجزات كما أكسبها قدرات أكبر على التأثير و الانتشار، ولكن ظلت الثخصية المقسة مثار جدلا كبير في الكيفية التي تعالج بها در اميا وتقدم سواء كانت هذه المعالجة عبر سياق ديني يعتمد على الكتب السماوية في سرد تجلياتها والاحداث التي رافقتها وتفسير الظروف المحيطة بها ام كان سردا تاريخيا ينطلق من انسنة هذه الثخصية المقدسة وتقديمها في اطـار در امي يمكن ان يتماها معها المتلقي ويشعر بكمية الوجع الذي تحمله كي يستطيع معها صـانع العمل ايصـال الرسـالة و الفكرة من مغزى تناول هذه الشخصية ومن هنا انطلق الباحث في طرح مشكلة بحثَه على شكل السؤال التالي:

ما الكيفية التي يتم من خلالها تقديم معالجة اخر اجية لثخصية المقدس في الخطاب الدرامي ؟

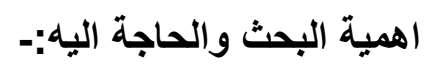

تكمن اهمية هذا البحث في انه يتاول الكيفية التي يتم بها تقديم معالجـة اخر اجية للثخصية المقدسة في الخطاب السينمائي لما تمثله هذه الثخصية من اهمية كبيرة سواء على المستوى الفكري و العقائدي.

$$
\text { اهداف البحث:- (1) }
$$

يهدف البحث الى در اسة الكيفيات التي ينم فيها المعالجات الاخر اجية لثخصية المقد في الخطاب الدرامي.

$$
\text { الحد الزماني: الأفلام المنتجة عام 9 ـ . الحكاني: الجمهورية الإسلامية الاير انية }
$$

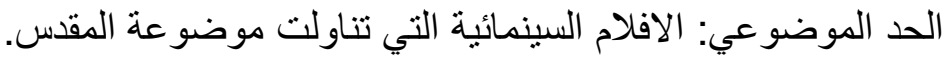

تحديد المصطلحات:-

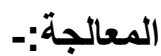

لغـة: عرفت المعالجة لغويـة بـ "عـالج معالجـة و علاجـا: زاولـه ومارسـه"'، و المعالجـة لسـان العرب " لغـة من العـلاج، المـر اس و الدفاع و عـالج الثـيء معالجـة وعلاجـا: أي زاولـه و عانـاه وكل شـيء زاولتهه ومارسته فقد 
اصطلاحا: المعالجـة بحسب خيريـة البثـلاوي" وصف سردي كامل لقصـة الفيلم مكتوبـة كمـا لو كان الكاتب يتصور احداثها بصريا في اثناء تطور ها، والمعالجة تتطور بعد ذلك، لتصبح سيناريو الفيلم الذي يتضمن وصفا دقيقا تفصيلياً لعملية السرد" " أما كيفن جاكسون فقد عرف المعالجة وفقا للكيفية التي يتعامل بها كاتبو السيناريو مع شركات الإنتاج بغية تتفيذ ما يكتبون "نسخة أولى من السيناريو لا يتجاوز في معظم الأحيان سوى صفحات

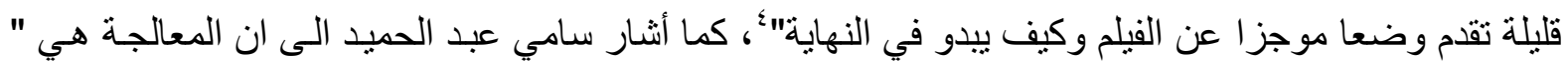

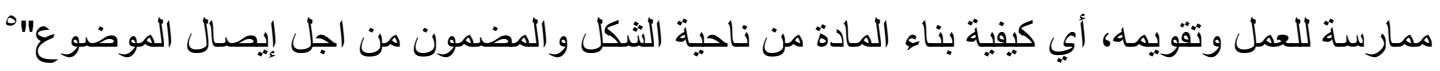
ويضع الباحث تعريفا اجر ائيا للمعالجة تتفق مع اهداف بحثه.

التعريف الاجر ائي: المعالجة هي الكيفية التي تقدم فيها الأفكار و المعاني في الدر اما التلفزيونية و السيمائية عبر استخدام عناصر الوسيط الى المتلقي وفق أسلوب جميل وشيق.

الثخصية:-

لغة:- الثخص "سواء الانسـان و غيره تر اه من بعيد وجمعه في القلة ( أشتخُص ) وفي الكثرة (شُخُوص) و) أشخاص). و ( شخص) بصره من باب خضع فهو (شاخص) اذا فتح عينيه وجعل لا يطرف. و(شخص) من بللٍٍ

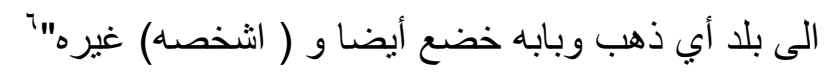

اصطلاحا:- الثخصية بمفهومها العام هي مجموعة " التراكيب و العمليات السيكولوجية الثابتة التي تنظم الخبرة

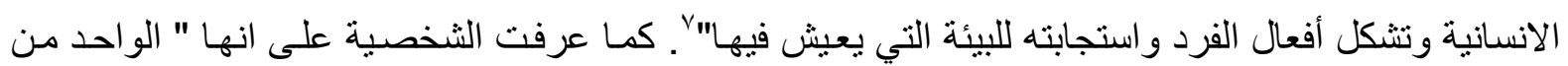
الناس الذين يؤدون الاحداث الدر اميـة المكتوبـة او على المسرح في صورة ممثلين" ا الشخصية عرفت أيضـا على أساس الاحداث وما تخلقه من سلوكيات تؤدي الى تطور الفعل التعريف الاجر ائي: الثخصية هي الابتكار الذي يقدمه السيناريست او صـانع العمل وتتميز بعدة مواصفات وابعاد على وفق ما يشترطه العمل الفني ويخدم الفكرة الرئيسة له

(المقدس:لغـة: تطرق أبن منظور الى المقدس في لسـان العرب تحـ: "مـادة قدس القدوس الطـاهر المتنزه عن العيوب و النو اقص، ونقدس للك أي نطهر أنفسنا للك، ونأخذ من هذا الثرح معنيبن للفظ الحرام: وهمـا ممنوع ومقدس، فالحر ام ما كان ممنوعاً، و المانع من انتهاك حرمته طهارته، و عليه لا يجوز للمـرء أن يمس الأشياء المقدسة، أو

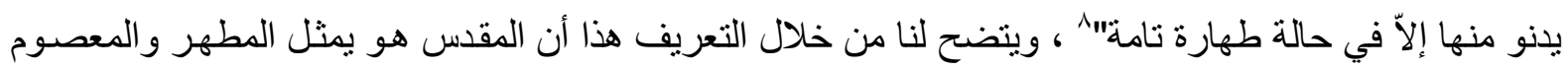
من الأخطاء.

اصطلاحاً:- يشير مصطلح المقد الى القوة المنزهة التي تمتلك في ذاتها الاحتر ام و الهيبـة والتي تسنطيع على فعل المعجزات، وتكون طاهرة ويقترن بها الحرمة، وارتبط المقدس بالدين والاله الذي يكون مرتبط بحياة الناس، وأيضا المنقذ للبشر من الاخطار والكوارث التي تحل بهم. 


\section{المبحثث الأول - مفهوم الشـخصية المقدسـة}

إرتبطت الثخصية المقسـة بحياة الثـوب منذ الازل، فمن حيـاة الثـعوب الاولى اخذ الانسـان بربط مفهوم حياته وسلوكه وكل ما يقوم به بهذه الثخصية المقدة، فهو فكر ومعتقد منتشر بين البشر على الرغم من اختلاف الزمان و المكان و المجتمعات ، ان الشخصية المقدسة تعتبر مثل العمود الرئيسي الذي يربط الثـوب ويوحد افكار ها ومعتقداتها ويجعل افعالها مربوطة به ويتخذه المجتمع قدوة ومثالا له .

و اذا رجعنا الى بدايات نشوء فكرة المقد فهو على الاغلب ينبع من الديانات وأماكن العبادة والطقوس الدينية "انه الفكرة الأم التي يتمحور حولها الدين فالأساطير و المعتقدات تحلل مضمونه على طريقتها والطقوس تستخدم خصائصده و الكهنة يجسدونه و المعابد والأمـاكن المقدسة والصروح الدينية توطده وتجذره في الأرض ومنه تنشأ الأخلاقية الدينية .. الدين هو تدبير المقس"(9) ، وقد حاول الانسـان في البدايات ان يضـع أجوبـة لكل تساؤلاته التي بر اها بحاجة الى توضيح من أجل ان برى هذا العالم الذي يحيط بـه بشكل بسمح لـه من الاستفادة

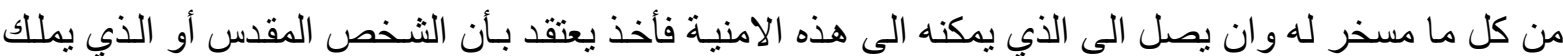

$$
\text { ادوات تفوق الادوات التي يملكها }
$$

فمنــ الو هلــة الاولـى اصـبح الانسـان دائم السؤال عـن طبيعـة الوجـود و أصـله وعن كل بنيـة الكـون وظو اهره مثنل الفصـول المناخيـة و الليـل و النهار و الطبيعـة ومـا تتبعـهـ مـن تقلبـات ، و الموت و الحيـاة ، فاعتقد الانسان في بادئ الامر "ان العـالم بكل مظـاهره المتنوعة يخضع لتر ابطات وقو انين وقو اعد معينة و اعتقد ان معرفته بتلك التر ابطات وقو اعدها تساعده في السيطرة على الطبيعة المحيطة بـه"(· ') و عند صـر اعه الدائم مـع الطبيعة وحقيقة مجرياتها واجتهاده في السيطرة والتغلب عليها ، وجدانـه غير قادر على التحدي وان الطبيعة دائما ما تتتصر عليه مهما بذل من جهد وقوة ، فاستسلم في نهاية الامر وارجع السبب في وجود قوة خفية هي التي تتحكم في الطبيعة وتمتلك الامكانيات الخارقة و الجبارة تسنطيع معها ان تتحكم في حياته.

وجعله يخاف منها ويتمنى رضاها عليه حتى يستمر في حياته بدون أن تغضب عليه وان تغدق عليه من النعم "قدم لها الأضـاحي و القر ابين و النذورات كي يحمي نفسـه من شر ها وأذاهـا و أعجب وأحب بعضـها الآخر فقدها مقدماً لها الأضاحي و النذورات و القر ابين والتراتيل كي يدوم خير ها عليه"(') فأخذ الانسـان الاول من الدين و الطقوس الدينية الوسيلة المفضلة للتقرب الى هذا المجهول الذي يمتلك القوة الخارقـة و والمؤثرة وقام بتقديسه طلباً لرضاه وخوفا على حياته ، و اجتهد في ابتداع مر اسيم للعبادة وتقديم القر ابين و الاضـاحي ومن هنـا تأصل مبدأ الدين في النفس البثرية وتركيبة المجتمع التي اصبح الدين فيها العمود الرئيسي في بنيته الاجتماعية اذ ان الذي يميز الانسان عن باقي المخلوقات هو العقل و الدين ،وقد ذكر هيجل في بحثَه عن الانسـان حيث قال

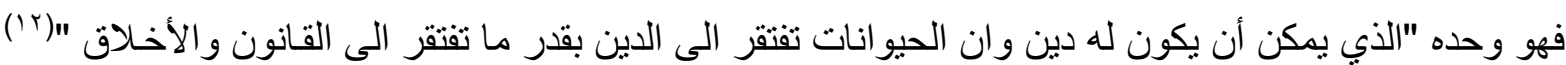
و هو أي الدين الذي يتميز به الانسان وهو الذي يمتلك هذا الدين بـالفطرة الانسـانية واصبح كل سلوكيات الحياة ومـا يترتب عليها من افعال بشرية مثل العمل وتكوين الاسـرة والعلاقات الاجتماعيـة وغير هـا هي شكل من 
اثكال العبادة والتدين، ومن هذا المنطلق نثـأت فكرة الاسـاطير التي ترتبط بالدين وبـالمعز ات التي يقوم بها المقس ، فبدأ الانسان بالانزياح نحو هذه الفكرة عسى ان يجد من خلالها تفسيرات للطبيعة وظو اهر ها و على الرغم من تعدد الديانات التي تحتوي عليها الاساطير الا أن الدين هو القاسم المشترك بينهم فهي

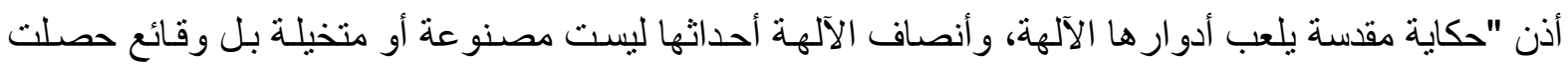
في الأزمنة الأولى المقدة إنها سجل أفعال الآلهة تلك الأفعال التي أخرجت الكون من لُجة العماء ووطدت نظام كل شيء قائم ووضعت صيغة أولى لكل الأمور الجاريـة في عـالم البشر.... و والأسطورة حكايـة مقدسـة تقليديـة

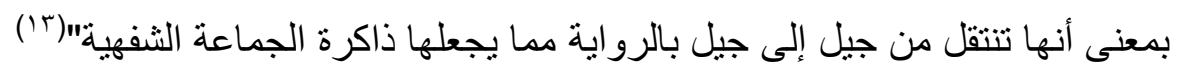
لقد حاول العلماء تفسير ظـاهرة الدين وتعريفه بصوره دقيقة وو اضحة ، فجاءت ار اءهم وتفسير اتهم متغايرة مـع بعضهم البعض فيرى شيشرون* ان الدين في جوهره، هو " الاهتمـام بطبيعـة مـا هو أسمى من

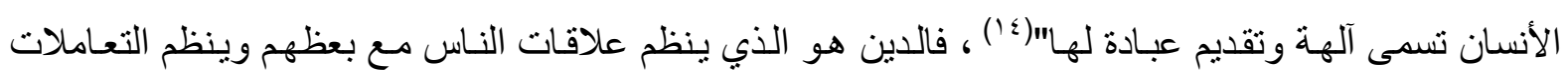
و العبادات لانه قائم على مبدأ الثواب والعقاب من قبل المتحكم القوي الذي يسيطر على حياة الناس والقادر على التصرف بأمور الدنيا

\section{المبحثث الثاني - توظيف عناصـر الوسيط السينيمائي لشـخصية المقدس}

تمكنت السينما مـن الولوج الـى كل العو الم و المتخيلات والاسـاطير و القصص القديمـة وتقديمها الى لى المتلقي بصورة حكاية فلمية لاتتعدى الثلاث ساعات ، مما جعل من هذا الوسيط وسيلة تقدم من خلالها تاريخ

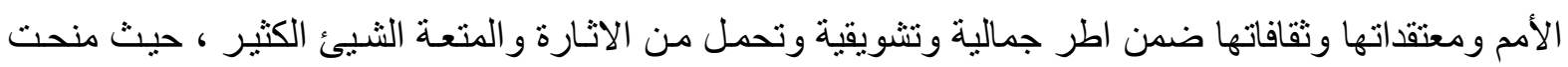
السينما للدول و المجتمعات الطريقة المثلى للوصول بحضارتها الى بـاق الدول " يعد فن السينما واحداً من أهم الفنون التي تلعب دوراً بارزا في حياة الانسان المعاصر ، لمـا تحضـى بـه من شعبية طاغيـة ،ولمـا تمارسـه من

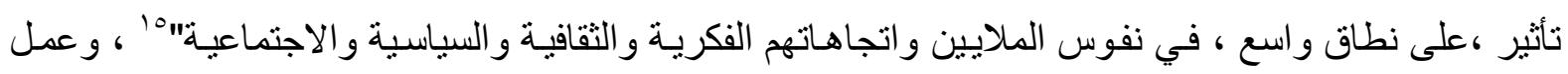
صناع الأفلام منذ انطلاق السينما على تجسيد كل القصص والحكايات التي تجعل المتلقي متمسكاً بهذا الوسيط ومتقبلاً له وبالتالي تمرير الرسالة المقصودة من انجاز الفلم.

ومن هذه القصص والحكايـات التي عملت السينما على تجسيدها هي القصص التي تحتوي على موضو عة المقدس ، فقد واجهت المتصدين لصناعة القلم عدة عقبات عند تتـاولهم المقدس بوصفها شخصية أو معتقد أو طقوس ، لمـا تحمله هذه الثخصية من هيبـة واحتر ام في نفس الثـعوب ، فهو يمثل الدين و الانتمـاء و الوجود و الكر امة فأنه لو لا" المقدس الذي توارثته الأجيال لمـا تمكنا من إمتلاك ذخيرة ثقافيـة زاخرة بالتقاليد

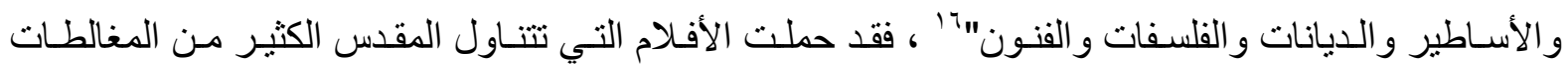
و المتغير ات على مستوى تمنيل الثخصية المقدة ، بسبب تنوع المجتمعات وأن كل مجتمع من هذه المجتمعات لهـا نظرة خاصـة الـى المقدس وكان هذا هو التحدي الأكبر الذي واجـه صناع الفلم ، فقي القرن الماضـي تم معالجة العديد من قصص الأنبياء وتقديمها في الأفلام مثل فلم (الوصسايا العشر) للمخرج (سيسيل دي ميل ) حيث تناول قصة النبي موسى. 
فنرى أن تجسيد الأنبياء وقصص حيـاتهم شكلت عقبـة امسام المخرجين لمـا تحمل مـن اختلافـات في مستوى الفهم و التفسير ، وأذا خرجنـا من قصص الأنبيـاء وذهبنـا الى الافلام التي عالجت الثخصية المقدسـة

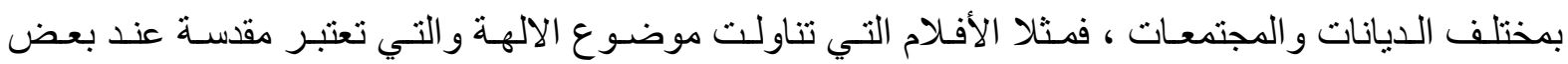
المجتمعات والتي حاولت ان تضفي صفة الانسنة لهذا الاله ، ففي فلم (الاوديسـة ) للمخرج (اندريسه شلوفسكي ) ،فقد قام المخرج في هذا الفلم بتجسيد الاله (فينوس) اله الحسن و الجمال ، على شكل أمر أة جميلة تمنلك صفات انثوية رائعة ، ولكن أعطاها في نفس الوقت القوة الخارقة التي يمكن فقط للمقدس أن يمتلكها ، و أيضـا في نفس القلم اعطى ملامح و هيئة صورية لاله مقد اخر وهو اله البحر(بوسيدون) حين جسده في البحر عند تكوين

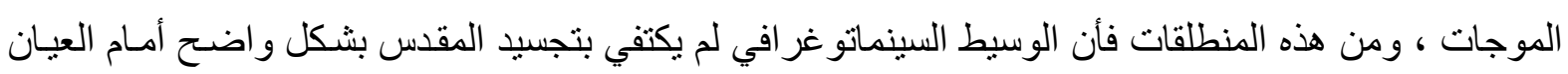
و انما عن طريق اشكال أخرى منل الصوت القادم من خارج الكادر أو الإضـاءة التي تكون حول المقدس أو أي

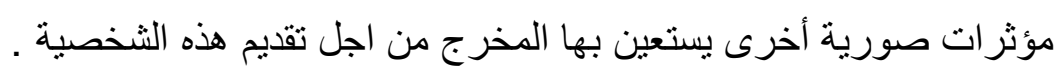
الرمز:-

شكل الرمز علامة مهمة في الوسيط السينمائي لما يمتلكه من إثـارة تعبيريـة يستطيع من خلالها صـانع

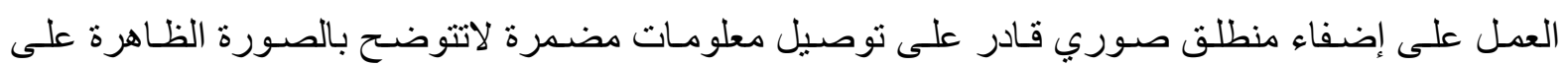

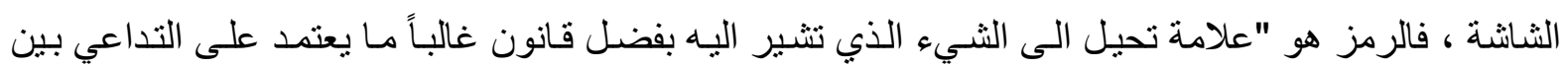

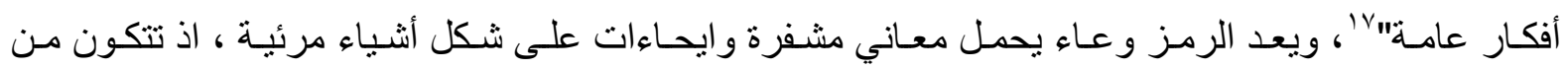
مجمو عة من علامات أو علامة واحدة تدل على معنى دلالي يكون الدال و المدلول المكون الرئيسي لهاء و أن الرمز يتصف بأنه" تمثيل لأفكار وهو وسيلة حين يضطلع بمهية نقل معنى اخر من خلاله"`'، أذن هو وسيلة ير اد منها نقل أفكار الى المتلقي الذي بدوره سوف يستلم هذه العلامـة ويفسرها هـن مرهن مرجعياته وثقافتة ، اذا ما علمنا أن هناك ثلاث أنواع من المتلقين (المتلقي النموذجي ،المتلقي العادي، المتلقي البسيط) ، وزخرت أفلام الثخصيات المقدة باستعمال الرمز كما في فلم (الرسالة) للمخرج مصطفى العقاد حيث استخدم رمز سيف الامام علي(ع) للالالة على وجود الامـام في الحرب وانـه قد تقدم للقتال ، واستخدمها عوضـا عن اللجوء الى الصورة الثكلية الظاهرية لما لثخصية الامام علي (ع) من قدسية لدى المسلمين تمنع ظهور ها على

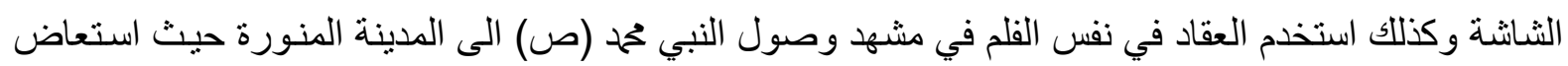

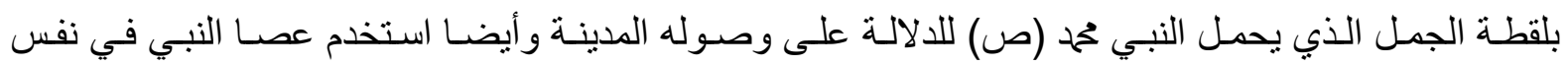
المشهد. وكلها رموز تدل على شخصية النبي ومـا تحمله من هيبة واحتر ام بين المسلمين ، وهنـاك أمثلـة فلميـة

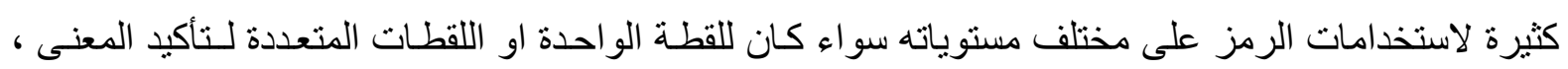
حيث أن الرمز يعتبر" إختز ال مرئسي يسـاعد صـانع الفيلم على تحديد الواقع و على نقل معلومـات هامـة دون الحاجة الى تمهيد تفسيري" "،فالرمز عنصر مهم في الافلام التي تعالج المقدس. 
تقوم فكرة السـرد من خـلال اشـكال التواصـل بين البشـر وعلاقـاتهم مـع بعضـهم البعض" أن مـا أنشـأ الانسانية هو السرد"' حيث أن البشر يعيشون بعالم مليئ بالحوادث وتجارب حياتية وقصص، ولم يجد الانسان غير الكلام لكي يحكي هذه القصص و التجارب ويسردها الى أبناء جنسه، واحتلت قصص الاسـاطير والخر افات الصدارة في مايتناقله الانسـان البدائي، حيث كانت الأسطورة هي المسيطرة على اغلب كلام البشر ولذا فأن الاساطير في المجتمعات الأولية " قصص مقدة ترجع استمر اريتها الحضـارية الى انتقالها من جيل الى اخر

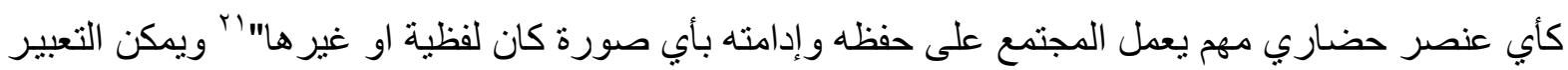
عن السرد بأنه حكايه، وحدد لنا (رومان جاكبسون)* ستة وظائف في عملية الاتصال التي يحتويها السرد وهي بطبيعة الحال تكون منتـابكة و ومتداخلة مع بعضها صـورية أو مرئية كانت أو تعتمد على الكلام أي اللغـة ،

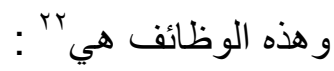
ا - الوظيفة التعبيرية أو الانفعالية:- تظهر مـع المرسل (محور الاتصـال) كونسه ذاتاً تنقل الرسـالة من مجموعـة علامات تثير الى موققه الخاص إز اء قضية معينة. r- وظيفة إقامة الاتصال وتأمين استمراره، أو قطعه، أو تغييره. r- وظيفة تعدي اللغة:- وترتكز على الرسالة كونها بؤرة لها وتتمحور في مناقثـة اللغـة وأضـاءتها ، وتتشمل تجنيس الفعل اللغوي وعناصر اللغة وقو اعدها. ع -الوظيفة التضمينية أو الندائية:- وتحدد العلاقات بين الرسـالة والمتلقي بالتوجهـ الى عاطفة المتلقي أو ذكائه، و هي علاقة تبرز التعارض بين الوظيفة المرجعية و الوظيفة العاطفية. وبناء على ما تقدم فأن السرد يلعب دور ا مهماً على مختلف مستوياته وأنسـاقه في الغور في شخصية المقدس و التمهيد اللى الأفعال الخارقة التي يقوم بها و أيضا في الدفع بحركة الصراع وصو لاً الى الذروة ومن ثم الحل .

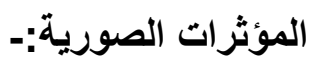
تعرف المؤثرات الصورية على أنها أي أضـافة أو حذف أو ادخـال معالجـات وتحسينات على الصسورة الاصلية التي تم تصوير ها أو انتاج صورة جديدة ، حيث ان المؤثرات هي "جزء عضوي من أفلام كثيرة، وهي

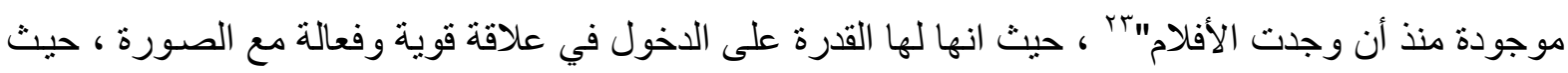

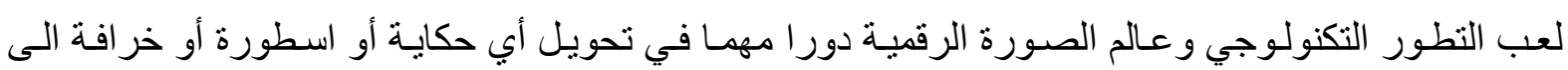

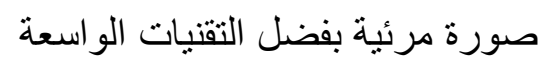

ومنحت صانع العمل الحرية الكبيرة في معالجة كل أنواع القصص وتحويلها الى منجز فلمي يمنلك من

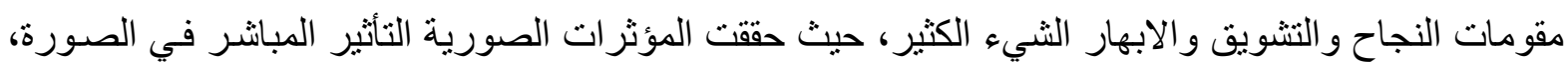
أضافة الى القدرة على تمثنل كل القدرات الخارقة التي تمنلكها الثخصيات المقدسة، ودخلت المؤثرات في كل مفاصل هذه الثخصية حتى في أدائها، و أيضـا خفضـت المؤثرات الصسورية كلف الإنتاج بصورة كبيرة مـع 
الاحتفـاظ بجودة ونقاوة الصورة "لا تتمكن المؤثرات الرقميـة من تخفيض تكاليف الإنتاج فقط، بـل من إنقاذ الإنتاج أيضاً. فحين توفي اوليفر ريد أثناء تصوير فيلم (المصـارع)، تم ادخـال صسورته رقمياً في المشـاهد التي تحتاج الى وجود شخصيته من أجل إتمـام الفيلم، وفي فيلم(السـاعات)، كان من الضروري لنيكول كيدمان أن تضع أنفاً نرقيعياً ليجعلها تشبه فرجينيا وولف، مع ان الثبه كان ضعيفاً جداً"؟

تمكنت المؤثرات الصورية من خلق عو الم جديدة كانت غير مألوفة عند انتاج الأفلام في السـابق حيث دخلت في بداية انتاجها على شكل مؤثرات ميكانيكية أي تصنع في الاستوديو أو التصـوير الخـارجي ، وتدخل في صناعتها كوادر كبيرة ومواد وتأخذ وقتاً كبير ا في إنجاز هـا ،ومن أمثلة هذه المؤثرات فلم حرب النجوم للمخرج جورج لوكاس الذي أنتج عام I IVV حيث بنى المجرة التي تجري فيها الحرب على شكل مصغر ات واشكال تتحرك ميكامنيكياً

ومن ثم دخلت المؤثرات الرقمية عن طريق الحواسيب واصبح معالجة مثثل هكذا قصص أكثر و اقعيـة وجمالية ، و اصبح تجسيد الثخصيات الخارقة شيئا في متناول اليد وتخلق الاثارة و أيضا ارتفاع مستوى التفاعل بين المتلقي و المنجز الفلمي، كما في فيلم (ماتركس)، حيث لم تقف المؤثرات الصورية الرقمية عند حد معين بـل هي في تطور دائم حتى دخلت في كل تفاصيل انتاج الصسورة لابل في الأداء الحركي للممثلين ، حيث يربط الممثل بمجسات حسية تسجل كل الحركات التي يؤديها ومن ثم نقلها الى الحاسوب وبعدها يتم تصنيع شخصيات افتر اضية في بر امج خاصة مصنعة لهذا الغرض " كثنف الكومبيوتر عن قدرته على الغاء الحقيقة والو اقع، عن طريق تصنيع و اقع افتر اضـي وخلق صسورة واقع لا تمثنل انعكاسـاً للواقع المـادي نفسـه، بـل نتيجـة لفكرة ينت ro" تحقيقها عبر برمجة الكومبيوتر

وضمن العناصر الرئيسية الداخلة في صناعة المؤثرات الصورية الرقمية هي الكروما *حيث أتاح هذه

التقنية المجال الكبير لتنفيذ كل مـا يريده المخرج لمعالجة كل انواع القصص سواء التي تحتوي على مشـاهد المعارك او تجسيد شخصيات ذات اشكال غريبـة وتمتلك أفعال خارقة، وبذلك حققت التقنية الرقمية مستويات عديدة في تحقيق الو اقعية و الجمالية في نفس الوقت. مؤشرات الاطار النظري:

1 - تمتلك الثخصـية المقســة صـفات خارقـة يعجز عنهـا الانسـان العـادي وتفرض على النـاس الهيبـة و الاحتر ام ، و انها الثخصية المنقذه من الاخطار .

r- - الثخصية المقدة هي نتاج الأديان وارتبطت في كثير من الاحيان بمجمو عة طقوس وشعائر يمارسها الانسان لنيل رضا المقدس.

r- دخول المؤثرات الصورية كعنصر مهم وحيوي في إبراز السمات الخارقة للشخصية المقدسة والافعـال

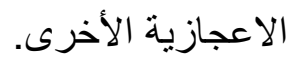




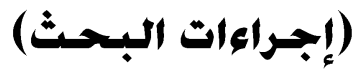

أولا : منهج البحث

من أجل تطبيق أهداف البحث وتقديم افضل الحلول الممكنة للمشكلة التي تناولها البحث اعتمد الباحث

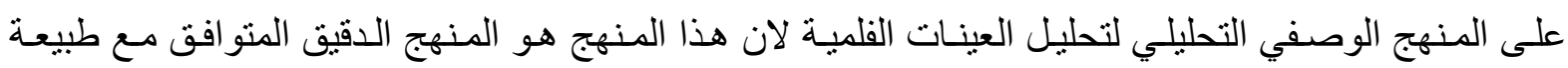
البحث ، و أيضا ان هذا المنهج يتمتع بمواصفات تحليلية للمادة المنتخبة لتطابق اهداف البحث .

ثانياً: مجتمع البحث

أهتم البحث على الافلام التي أنتجنها السينما الإير انية، عام 9 . . ب لأنها زاخرة بالعديد من الأفلام التي

تتضمن قصص الأنبياء و الثخصيات المقدة، حيث تم معالجة الثخصيات المقدة بشكل ابداعي متميز ، ويرى لهري الباحث انها ستكون عينة ممتازة وتحقق أهداف البحث وتتتمل على الحلول لمشكلة البحث.

ثُالثاً: عينة البحث

من أجل التو افق مع منهج البحث وايضـا للوصـول الى النتائج العلمية الرصينة والدقيقة اختار الباحث عينة قصدية لعدة اسباب يمكن توضيحها كما يأتي:

1- معالجة هذة العينة لنخصية مقدسة هي النبي سليمان (عليه السلام).

r- استخدام تقنيات ومؤثرات عالية المستوى لتنفيذ الافعال الخارقة للشخصية المقسة. أما العينة فهي فلم (مملكة النبي سليمان) للمخرج شهريار بحر اني

خامساً: وحدة التحليل

اعتمد الباحث في تحليل العينة ومن أجل الوصول الى النتائج المطلوبة لمشكلة البحث على وحدة تحليل

قياسية تتمثل في المشهد .

(تحليل العينة)

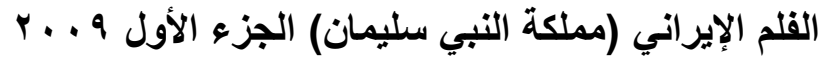

قصة القلم: - م

تدور احداث الفيلم في مرحلة تولي النبي سليمان(عليه السلام) للحكم بعد ابيه النبي داوود(عليه السـلام)،

وتتشأ ذروة الفيلم من الصر اع بينه وبين علماء اليهود الذين كانوا يطمعون بحصـة من حكم الثـب ويستعينون من اجل الوصول الى مآربهم بتسخير الجن والثياطين وتوظيفها لتأليب الناس ضد حكم سليمان(عليه السـلام) ، فيخوض النبي سليمان معهم حرب شرسـة ويقُتلَ فيها الكثير من اتباعة ، فيطلب من الله ان يسـاعده للانتصـار على الجن و الثياطين اللذين تلبسوا بشعبه ، ويسخر الله له الريح من اجل الانتصار في الحرب، وفي نهاية الفلم ينتصر النبي سليمان عليهم ويعطيه الله الخاتم الذي يجعله مسيطر ا على معشر الجن و الثيطان .

تحليل العينة: المؤشر الأول: تمنلك الثخصية المقدة صفات خارقة يعجز عنها الانسان العادي وتفرض على الناس 
الهيبة والاحتر ام ، و انها الثخصية المنقذه من الاخطار .

- بطبيعة الحال تفرض الثخصية المقسة الحظوة الكبيرة للاحتر ام و التبجيل بين الناس حيث كان ذلك

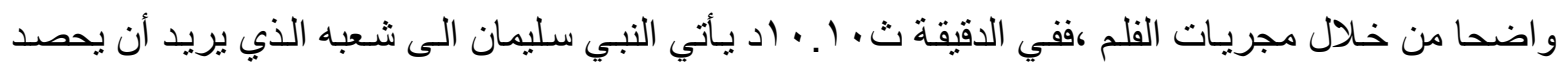
الحنطة ، و عند وصوله اليهم يفرحون بقدومه ويسلمون عليه كثير ا ويظهر الاحتر ام الكبير و الهيبة ، ثم يطلبون منهه الدعاء قبل ان يجنوا المحاصيل من اجل البركة ، فيقوم النبي سليمان بالدعاء و الطلب من الله ان تحل البركة وان يسـاعدهم في عمهم ، ومن ثم يطلب منهم ان يبدأو بالعمل فيفرح الناس لهذا الدعاء ويرحبون بمساعدة النبي لهم في جني المحصول، ومن هنا يظهر مدى تقديس الثعب لثخصية النبي سليمان لأنه مرسل من الله الذي يعبدونه ويرجون رضاه.

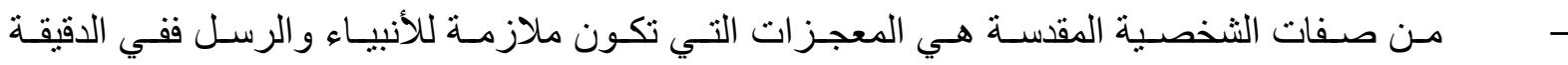
ث • 1 . ب rد وحين شعور النبي سليمان بازدياد الخطر القادم الى مملكته من قبل اليهود الذين ينازعونه على ملكه ، فيجلس لوحده في الليل و الجو ممطر، وهو يفكر في حل لإنقاذ شعبه من الخطر القادم اليهه وفي لحظات التأمل ينتقل الى لقطة في السماء الملبدة بالغيوم واذا بها تتقشع ويأتي صوت من السماء ، فيعرف النبي سليمان ان المتكلم هو الله ، حيث ان الله لا يتكلم مع البثر العاديين وان المرسلين فقط والانبياء لهم هذه الخصوصية و هذه معجزة من الله للأنبياء المقسين ، يتحدث الله الى النبي انه اختاره لمحبته لـه هو و ابيه داوود وانـه فضلهم على كثير من عباده الصالحين حين منحه الكتاب والنبوة ، ويخبره ان كثير من الناس يتبعون وساوس الثبطان، فيطلب النبي سليمان من الله ان يهبه ملكاً عظيما لان يهبه لاي احد الى نهاية الدنيا، ويستمر النبي بالحديث انلك ون ون انت الوهاب ،و هاب الجنة الموعودة. المؤشر الثاني: الثخصية المقدسة هي نتاج الأديان وارتبطت في كثير من الاحيـان بمجموعة طقوس وشعائر يمارسها الانسان لنيل رضا المقدس.

- ارتبط وجود المقدس بالدين وبـالطقوس وبالحتميـة التي أدت السى وجود المقدس حيث يأخذ الطهارة و التنزيـه مـن مجموعـة أفعال يؤديها ترتبط ارتبـاط وثيق بحيـاة النـاس ومسـاعدته لهم ويكون هو الحـامي لهم

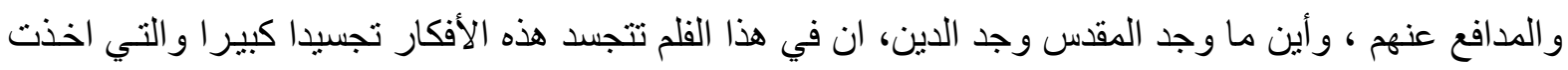
القصة أي قصة النبي سليمان من القرأن الكريم حيث يخبرنا الله سبحانه وتعالى عن مدى المصـاعب و المشـاكل التي تعرض لها سليمان النبي، ولكن بالنهايـة انتصر النبي بأر ادة الله وبالتوكل عليه ، ووجد الدين و الطقوس و الافعال الشعائرية في هذا الفلم في مشاهد عدة ، فقي الدقيقة ·. • r د في مشهد ليلي يجلس النبي سليمان بجانب صخرة وهو يطلب المساعدة من الله كي ينقذ الناس اللذين امنو به وبالدين الذي جاء بـه اليهم ولكي يثبت للناس صدق الرسالة التي جاء بها من عند الله ، ويتوسل النبي بالله لكي يقف بجانبه حتى يستطيع اكمال رسـالته الدينية

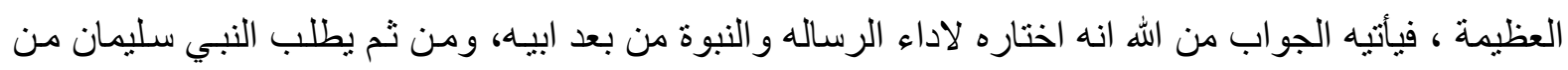
قادة جيشه ان بطلب بقادة البلدات والقرى ان يجتمعو الكي يطلب منهم ان يجتمعو على كلمـة واحدة ونصرة هذا الدين حتى يفوزوا بالجنة الموعودة . 
المؤشر الثالث: دخول المؤثرات الصورية كعنصر مهم وحيوي في إبراز السمات الخارقة للثخصية المقسـة و الافعال الاعجازية الأخرى.

تلعب المؤثرات الصـورية دورا هامـا في تجسبد الأفعال الخارقة والمعجزات التي تكون متلازمة مـع المقدس ، حيث أضافت هذه المؤثرات الواقعية والجماليـة في نفس الوقت ، و أصبحت عنصـر ا مسـاعدا لصـانع العمل في معالجـة الأفلام التي تتنـاول هذا القصص ، وتتيح هذه المؤثرات الصسورية المسـاحة الواسعة لتنفيذ المعاجز بصورة دقيقة من أجل توصيل رسالة وهدف المنجز الفلمي .

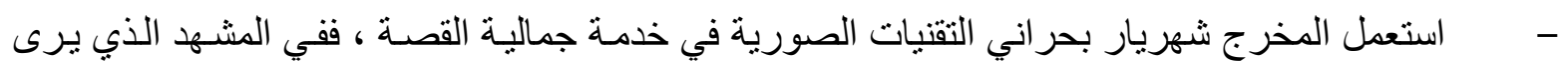
فيه نبي الله سليمان رؤيا تتبؤه بأن الخطر قادم وان معشر الجن سيهجم على مملكته ، هذا المشهـ في الدقيقة • ع ـ إد حين يأتي النبي سليمان راكباً على الحصان مع اخوته فيقف وينزل من الحصـان فيحس بشيئ غريب فينظر الى الو ادي و أذا بحصان ابيض واقف ثم فجأة يركض وخلفة مجموعة من الاحصنة وفي لقطة متوسطة تظهر وهي تركض وسط النير ان الملتهبـة ولونها ينقلب الى احمر وكأنها تحترق وتستمر في الركض وسط يط النيران، ثم بأنتقاله صورية تبدأ هذه النيران بالاختفاء تدريجيا وبلقطة عامـة ينتهي هذا المشهـد المر عب و الذبي يحمل رساله من الله الى النبي بأن الخطر قادم ، فنرى أن المخرج قد استفاد من تقنيـة المؤثرات الصسورية في التلاعب بالصورة وتوصيل الدلالة التي أراد توصيلها عن طريق هذا المؤثر.

(النتمائج)

ا ـ تتميز الثخصية المقسة بعدد من الصفات التي تشكل بمجلها خوارق يعجز الانسان عنها وعن الاتيان بها r- تعد الأديان النتاج الطبيعي للثخصية المقدة والتي ترتبط بمجموعة من الطقوس والثـعائر التي يمارسها الانسان لنيل رضا المقس.

r- يكثف التوظيف التعبيري لعناصر الوسيط السينمائي عن السمات المميزة للشخصية المقدة. عـ للثخصية المقدسة اكثر من مستوى سردي للاخبار عنها او عن الاعجاز الذي ينتج عنها جراء حياتها

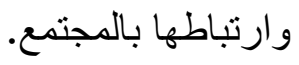

هـ تعد المؤثرات الصورية والصوتية عنصر مهم في ابر از السمات لخارقة للثخصية المقدة.

\section{(الاستنتاجـات)} ا - يشكل المكان وتحو لاته البنيه الأساسية لموضوعة الثخصية المقسة في الفيلم السينمائي.

זـ البناء السردي للثخصية المقدة نسق تتابعي للاحداث وفق الضرورات الفنية التي يرتنيها صانع العمل. r- انتاج بنية صوتية وصورية ثابتة في بنائية المشهد بما يناسب الاحداث وتكون ذات ناثير كبير على المتلقي. ع ـ تحقق عناصر الوسيط السينماتو غر افي تأثير ا دراميا ودلاليا وجماليا في التعبير عن الثخصية المقسة. 
ع- بنية الثخصية المقدسة والتحو لات التي تعيثـها تشكل انطلاقـة مهمة في سـرد الاحداث الدر امية وفق صياغات فنية يرتنيها صانع العمل.

هوامش البحث:

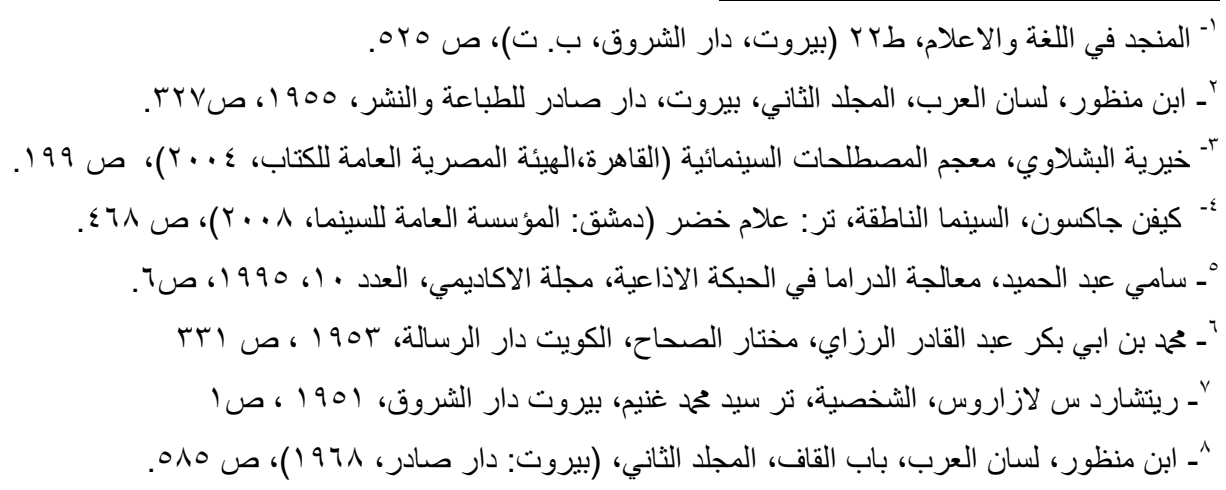

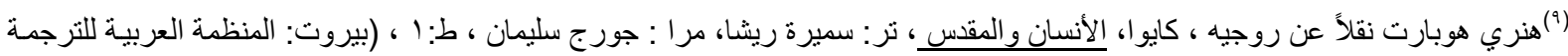

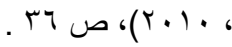

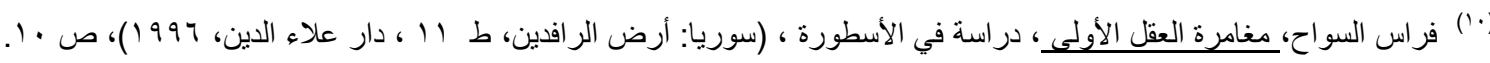

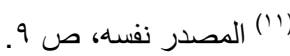

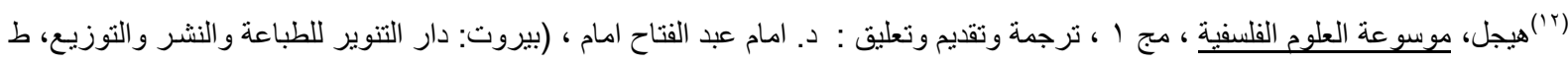

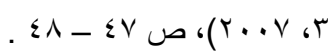

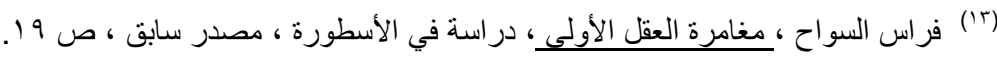

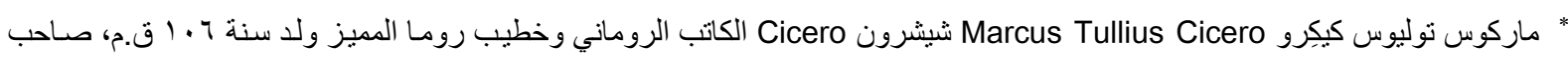
إنتاج ضخم يعتبر نموذجا مرجعيا للتعبير اللاتيني الكلاسيكي للمزيد ينظر: الموسوعة الحرة .

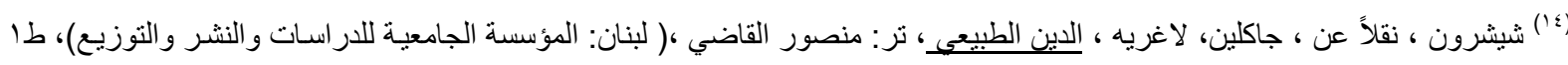

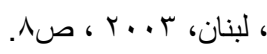

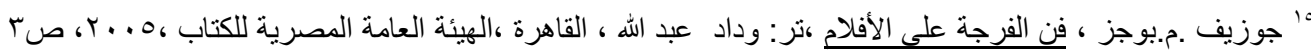

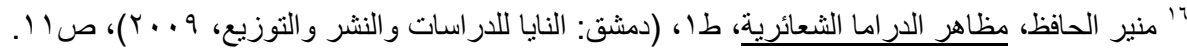

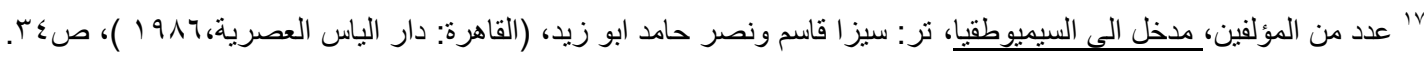

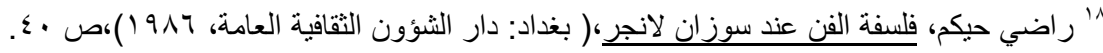

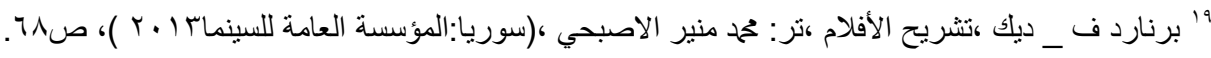

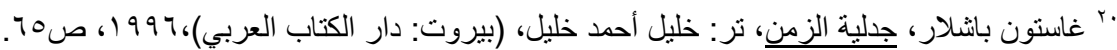

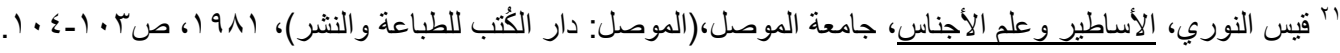
* هو عالم لغوي، وناقد أدبي روسي و هو من رواد المدرسة الثكلية الروسية ـوقد كان أحد أهم علماء اللغة في القرن العشرين وذللك لجهوده الرائدة في تطوير التحليل التركيبي للغة والثعر و الفن

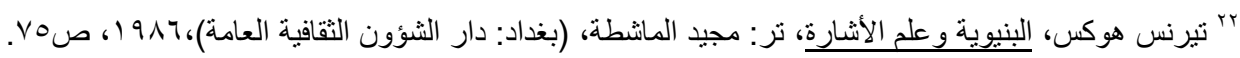

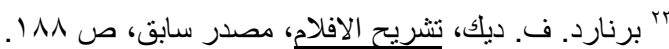

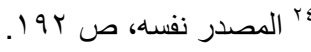

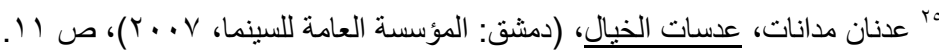
* هي عبارة عن تصـوير المشهـ على خلفية ذات لون أخضر أو أزرق ، ثم بعد ذلك يتم حذف هذه الخلفيـة ببرامج الجرافيك ودمـج المشـاهد

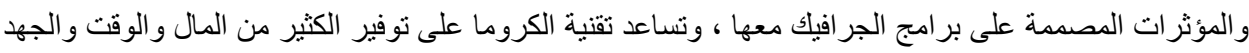




\section{المبسادر والمراجع}

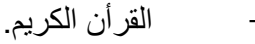

المعاجم و القو اميس

1 - ابن منظور، لسان العرب، المجلد الثاني، بيروت، دار صادر للطباعة والنشر، 1900 أ.

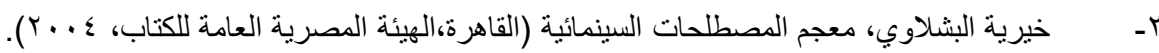

r- لويس معلوف، المنجد في اللغة والاعلام، طبץ (بيروت، دار الشروق، ب. ت).

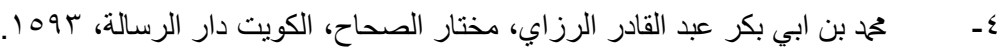

المصادر العربية والمترجمة

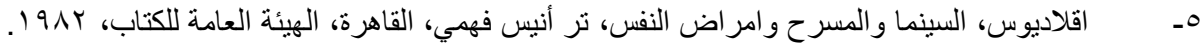

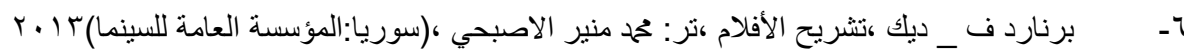

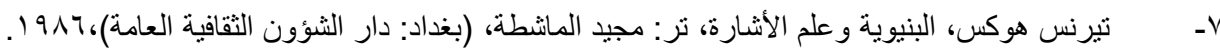

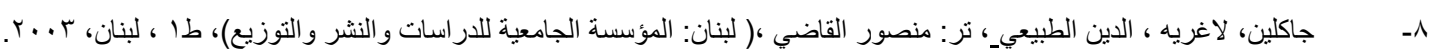

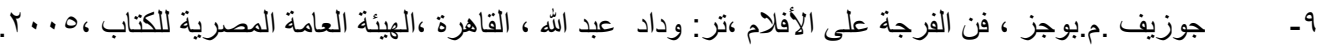

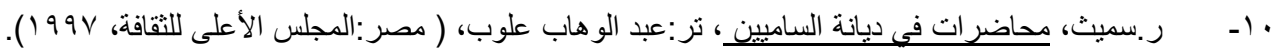

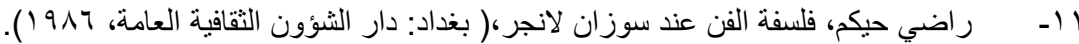

r I ا- ريتشارد س لازاروس، الثخصية، تر سيد محمد غنيم، بيروت دار الثروق، 1901.

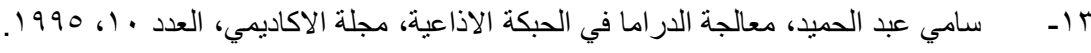

ع (- شاكر مصطفى سليم ،قاموس الأنثروبولوجيا_، طا ، (جامعة الكويت ، 1911 ).

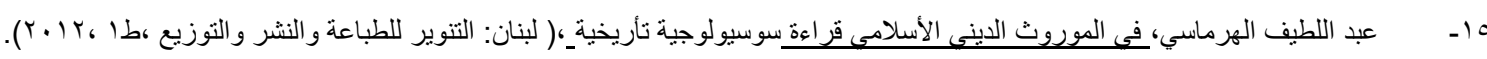

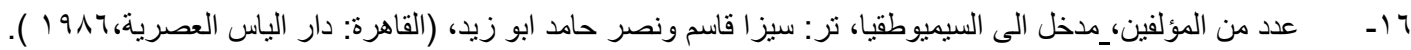

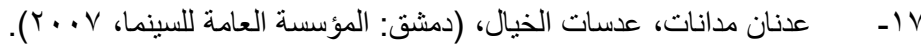

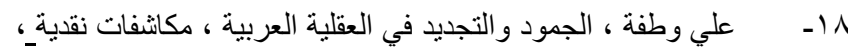

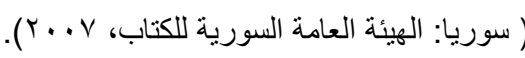

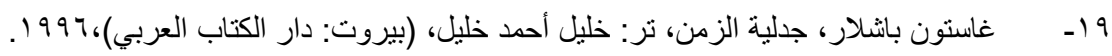

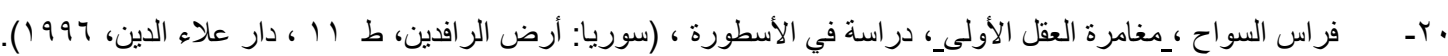

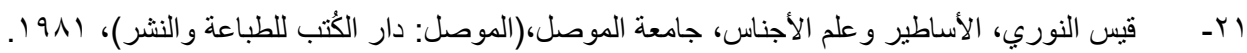

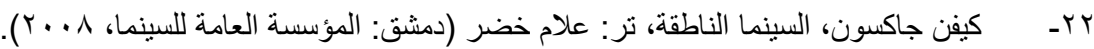

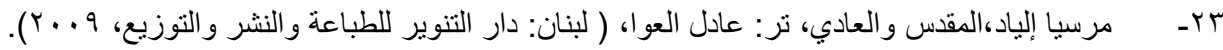

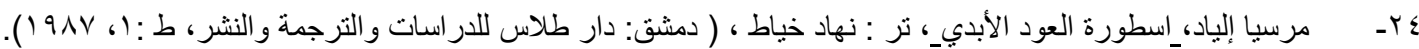

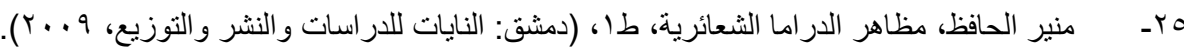

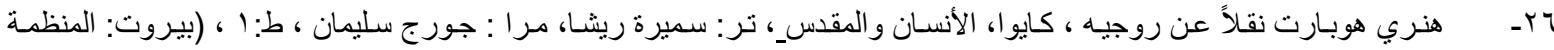

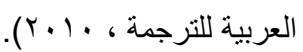

V V- هيجل ، موسوعة العلوم الفلسفية ، مج ا ، ترجمة وتقديم وتعليق : د. امام عبد الفتاح امسام ، (بيروت: دار التنوير للطباعة والنشر

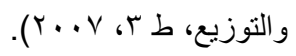

1 Y - يوسف شلحد، بنى المقدس عند العرب قبل الأسلام وبعده، ( بيروت : دار الطليعة ، ط: ، 997 ( ). 